Marquette University

e-Publications@Marquette

$11-15-2018$

\title{
Reactive Pathways in the Bromobenzene-Ammonia Dimer Cation Radical: Evidence for A Roaming Halogen Radical
}

\author{
Silver Nyambo \\ Marquette University \\ Brandon Uhler \\ Marquette University \\ Lloyd Godfrey Muzangwa \\ Marquette University \\ Maxim Vadimovich Ivanov \\ Marquette University \\ Bradley K. Welch \\ Missouri University of Science and Technology
}

See next page for additional authors

Follow this and additional works at: https://epublications.marquette.edu/chem_fac

Part of the Chemistry Commons

\section{Recommended Citation}

Nyambo, Silver; Uhler, Brandon; Muzangwa, Lloyd Godfrey; Ivanov, Maxim Vadimovich; Welch, Bradley K.; Dawes, Richard; and Reid, Scott A., "Reactive Pathways in the Bromobenzene-Ammonia Dimer Cation Radical: Evidence for A Roaming Halogen Radical" (2018). Chemistry Faculty Research and Publications. 981.

https://epublications.marquette.edu/chem_fac/981 


\section{Authors}

Silver Nyambo, Brandon Uhler, Lloyd Godfrey Muzangwa, Maxim Vadimovich Ivanov, Bradley K. Welch, Richard Dawes, and Scott A. Reid 
Marquette University

e-Publications@Marquette

\section{Chemistry Faculty Research and Publications/College of Arts and Sciences}

This paper is NOT THE PUBLISHED VERSION; but the author's final, peer-reviewed manuscript. The published version may be accessed by following the link in th citation below.

Journal of Molecular Structure, Vol. 1172 (November 15, 2018): 113-118. DOI. This article is @ Elsevier and permission has been granted for this version to appear in e-Publications@Marquette. Elsevier does not grant permission for this article to be further copied/distributed or hosted elsewhere without the express permission from Elsevier.

\section{Reactive Pathways in The Bromobenzene- Ammonia Dimer Cation Radical: Evidence for A Roaming Halogen Radical}

Silver Nyambo

Department of Chemistry, Marquette University, Milwaukee, WI

Brandon Uhler

Department of Chemistry, Marquette University, Milwaukee, WI

Lloyd Muzangwa

Department of Chemistry, Marquette University, Milwaukee, WI

Maxim Ivanov

Department of Chemistry, Marquette University, Milwaukee, WI

Bradley K. Welch

Department of Chemistry, Missouri University of Science and Technology, Rolla, MO

Richard Dawes

Department of Chemistry, Missouri University of Science and Technology, Rolla, MO

Scott A. Reid

Department of Chemistry, Marquette University, Milwaukee, WI 


\section{Abstract}

Photoinitiated reactions in van der Waals complexes provide a means to examine reactive pathways from welldefined initial geometries. In recent work, we re-examined reactive pathways following resonant two-photon ionization (R2PI) of the chlorobenzene-ammonia $\left(\mathrm{PhCl} \cdots \mathrm{NH}_{3}\right)$ dimer. The dimer cation radical reacts primarily via $\mathrm{Cl}$ atom loss, and additional channels corresponding to $\mathrm{HCl}$ and $\mathrm{H}$ atom loss were identified. The structure of the reactive complex was confirmed as an in-plane $\sigma$-type, and computational studies of the dimer cation radical potential energy landscape revealed two nearly isoenergetic arenium ion intermediates (or Wheland intermediates). The intermediate produced from ipso addition was not stable with respect to either $\mathrm{Cl}$ or $\mathrm{HCl}$ loss, and the relative branching observed in experiment was well reproduced by microcanonical transition state theory (TST) calculations. Here, we report experimental and computational studies of the related $\mathrm{PhBr} \cdots \mathrm{NH}_{3}$ dimer, examined for the first time. We present evidence that the dimer structure is also an in-plane $\sigma$-type. However, in contrast to the $\mathrm{PhCl} \cdots \mathrm{NH}_{3}$ system, calculations predict that the structure of the reactive intermediate corresponds to a distonic ion-radical complex, where the radical density is largely localized on the bromine atom. The calculated barrier to $\mathrm{HBr}$ loss is sufficiently high to render this channel nearly insignificant (less than 1\% branching) in TST calculations, yet experiment shows a sizable (37\%) branching into this channel. We rationalize these results in terms of a roaming $\mathrm{Br}$ radical mechanism for $\mathrm{HBr}$ formation.

\section{Keywords}

Halobenzenes, Nucleophilic substitution, Roaming radical

\section{Introduction}

The study of van der Waals clusters has provided important insight into the strength and directionality of intermolecular forces, and detailed experimental data (binding energies, vibrational and electronic spectra, etc.) on these systems provide important benchmarks for theoretical validation [1], [2], [3], [4], [5], [6], [7], [8]. Additionally, clusters provide a means to initiate reactivity from relatively well-defined initial geometries [9], [10], [11], [12]. Prototypical systems in this regard are the dimers of halobenzenes with ammonia (i.e., $\mathrm{PhX} \cdots \mathrm{NH}_{3}$ ) which upon ionization can react via a classic $\mathrm{S}_{\mathrm{N}} 2$ mechanism proceeding through an arenium ion (Wheland) intermediate [13], [14], [15], [16], [17], [18], [19], [20], [21], [22], [23], [24], [25]. Until recently, it has been thought that the structure of these dimeric complexes were $\pi$-type, where the ammonia is located above the plane of the aromatic ring. This was dispelled by studies of the Cockett group [26] (on fluorobenzene-ammonia) and our group [27] (on chlorobenzene-ammonia), which showed, via multidimensional Franck-Condon simulations of the excitation spectra, that the reactive complex corresponds to an in-plane $\sigma$ type.

We recently re-investigated the reactive pathways in the wellstudied [13], [14], [15], [16], [17], [18], [25], [28] chlorobenzene-ammonia dimer cation radical using resonant two-photon ionization (R2PI) and electronic structure calculations (density functional theory, DFT) [27]. In addition to the well-studied $\mathrm{Cl}$ loss channel (producing protonated aniline) [13], [14], [15], [16], [17], [18], [25], [28], a second channel corresponding to HCl loss (producing aniline cation radical) was identified for the first time in R2PI studies of the 1:1 complex, and a third channel, $\mathrm{H}$ atom loss, was also identified. The reactive potential energy landscape was extensively characterized by computational methods, and two nearly isoenergetic arenium ion (Wheland) intermediates were found. At the energy accessed experimentally, the intermediate produced from ipso addition was not stable with respect to $\mathrm{Cl}$ or $\mathrm{HCl}$ loss, and the relative observed branching between these channels (1:5.6 with $\mathrm{Cl}$ loss dominant) was 
well reproduced by microcanonical transition state theory calculations. The reactive pathways following photoionization in this system are summarized in $\underline{\text { Scheme } 1 .}$.

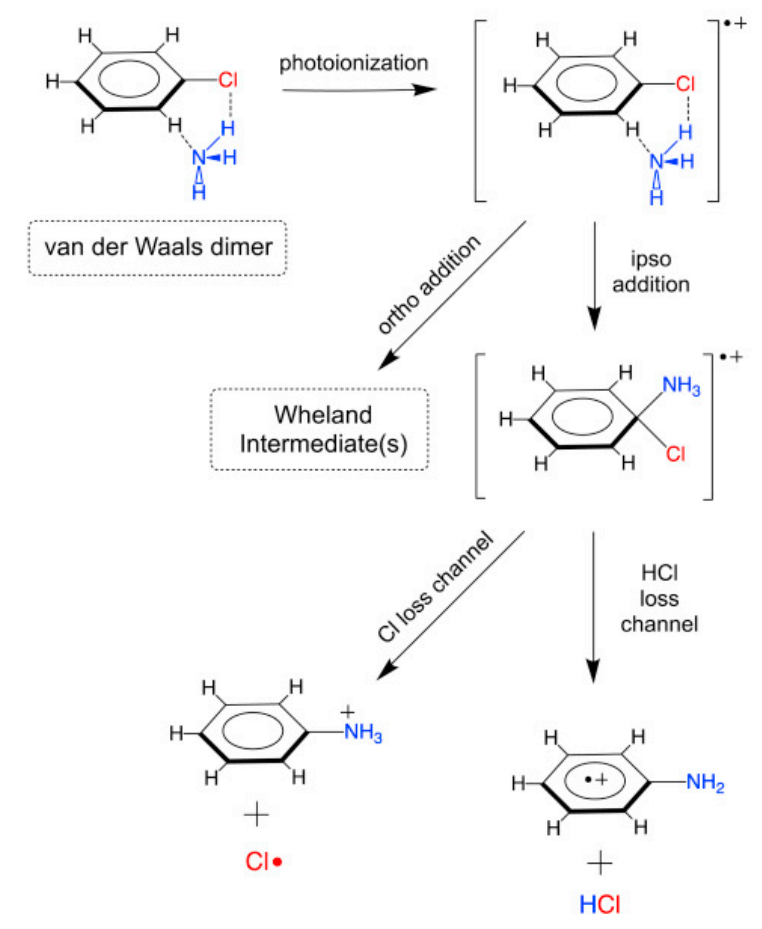

Scheme 1. Illustration of reactive pathways in the chlorobenzene-ammonia dimer. Upon photoionization, addition occurs leading to one (or more) Wheland intermediates. Only the structure produced from ipso addition is shown. These intermediates react to give the final set of products: protonated aniline $(+\mathrm{Cl})$ or aniline cation radical $(+\mathrm{HCl})$.

To date, no experimental studies have probed complexes between bromobenzene $(\mathrm{PhBr})$ and ammonia, primarily due to the fact that the $\mathrm{S}_{1}$ lifetime of $\mathrm{PhBr}$ is very short ( 30 ps) [29], [30] and it is therefore difficult to resonantly ionize with nanosecond lasers [31], [32], [33], [34]. Our initial interest in this system stemmed from the possibility of accessing halogen bonded structures. Thus, in the present work, we examine the formation and fate of the ionized complexes of $\mathrm{PhBr}$ and $\mathrm{NH}_{3}$ using one-color R2PI spectroscopy, supported by DFT, timedependent DFT, and $a b$ initio calculations at the explicitly-correlated coupled-cluster level, as well as FranckCondon simulations. Consistent with other $\mathrm{PhX} \cdots \mathrm{NH}_{3}(\mathrm{X}=$ halogen) dimers, we find that the observed complex is of a $\sigma$-type. However, the structure of the ionic intermediate predicted via theory is very different from that in the $\mathrm{PhCl} \cdots \mathrm{NH}_{3}$ system, being a distonic ion-radical complex, where the radical density is largely localized on the $\mathrm{Br}$ atom. Calculations predict a sizable barrier to $\mathrm{HBr}$ elimination from this intermediate, sufficient to yield very little statistical branching into this channel, yet we observe a branching for the molecular channel (37\%) which is significantly larger than in the analogous $\mathrm{PhCl} \cdots \mathrm{NH}_{3}$ system (15\%). Given the structure of the intermediate, and the lower energy exit channel to Br elimination, we postulate the existence of a roaming radical mechanism to explain the increased yield of the molecular channel.

\section{Experimental and computational details}

The experimental setup has previously been described in detail [27]. Our R2PI setup comprises a linear time-offlight mass spectrometer (TOFMS) coupled with a supersonic molecular beam source. The expanded mixture was generated by passing a $1-5 \% \mathrm{NH}_{3} / \mathrm{He}$ premix through liquid bromobenzene (Aldrich, $99 \%$ ) contained in a 
stainless-steel bubbler held at $25^{\circ} \mathrm{C}$. The backing pressure was varied between $\sim 2$ and 5 bar. lons were extracted and accelerated using a conventional three-plate stack, and flew through a $1 \mathrm{~m}$ field-free drift region prior to striking a dual Chevron microchannel plate (MCP) detector. The detector signal was amplified $(x 20)$ using a fast preamplifier (Femto HVA-500M - 20B), and integrated using a boxcar system (Stanford Research SRS250) interfaced to a personal computer. The laser system consisted of an etalon narrowed dye laser (Lambda Physik Scanmate 2E) pumped by a third harmonic of a Nd:YAG laser (Continuum NY-61). Coumarin 540A was used for the dye laser; its lasing range was $\sim 530-550 \mathrm{~nm}$. The output of the dye laser was then frequency doubled, giving an output wavelength range of $265-285 \mathrm{~nm}$. The doubled laser beam of energy range $\sim 0.5 \mathrm{~mJ}$ was loosely focused into the chamber by a $2 \mathrm{~m}$ plano-convex lens. An in-house LABVIEW program controlled data acquisition and stepped the laser wavelength; typically, the signal from twenty laser shots was averaged at each step in wavelength.

Our experimental findings were supported by two types of electronic structure calculations. DFT calculations were performed using the GAUSSIAN09 software package on the MU Pere high speed cluster [35]. Geometry optimizations were carried out using the M06-2X method [36] with the aug-cc-pVDZ and aug-cc-pVTZ basis sets. The performance of M06-2X for electronic excitations, including Rydberg and Charge Transfer excitations, has recently been benchmarked [37], and performed well on the similar chlorobenzene-ammonia system [27]. The MOLPRO package [38] was used to perform single-point energy calculations using the explicitlycorrelated coupled-cluster (U)CCSD(T)-F12a/VDZ-F12 method [39], [40]. The small-core pseudo-potential (PP) basis by Peterson was used for bromine [41]. Calculated coupled-cluster binding energies were corrected for zero-point energy (ZPE) using DFT. The vertical excitation energies and the electronic spectra of the dimers were calculated by employing Time-dependent DFT (TD-DFT) method at M06-2X/aug-cc-pVDZ level of theory. For the cation radical states, calculations were also performed using a calibrated [42], [43], [44] B1LYP functional (B1LYP-40), with a 6-31G(d) basis set. R2PI excitation spectra were simulated by performing multidimensional Franck-Condon calculations using the Pgopher program [45].

\section{Results and discussion}

In our previous work on the $\mathrm{PhCl} \cdots \mathrm{NH}_{3}$ system, we found that upon ionization the majority of dimer cation radicals reacted, leading to a very small signal in the time-of-flight mass spectrum at the parent mass/charge ratio $(\mathrm{m} / \mathrm{z})$. Given the difficulty in ionizing $\mathrm{PhBr}$, and the concomitant decrease in signal, it was not possible to measure an R2PI spectrum on the parent $m / z$. However, consistent with our prior findings for $\mathrm{PhCl} \cdots \mathrm{NH}_{3}$, a strong signal could be detected in the aniline cation radical and protonated aniline channels, as shown in Fig. 1, indicative of $\mathrm{HBr}$ and $\mathrm{Br}$ loss, respectively, from an ionized precursor. We provide evidence below that this signal arises from the ionized $\mathrm{PhBr} \cdots \mathrm{NH}_{3}$ dimer.

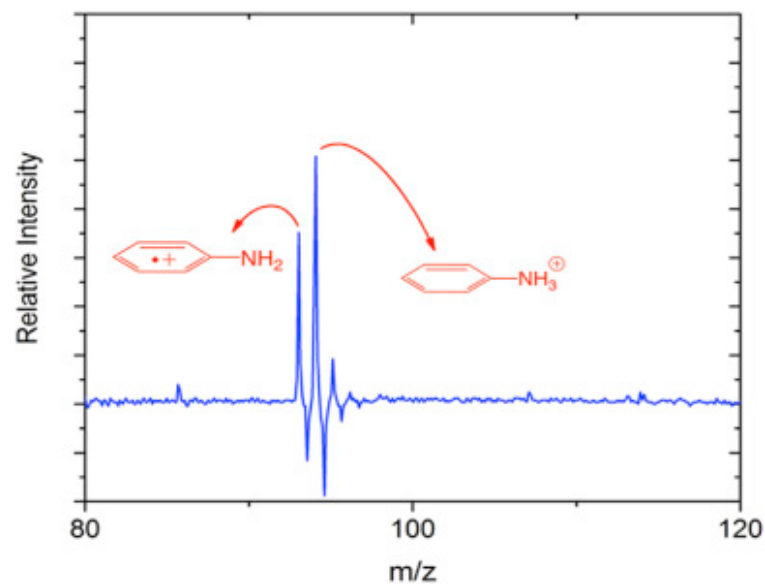


Fig. 1. Time-of-flight mass spectrum obtained following two-step ionization at a wavelength of $269.5 \mathrm{~nm}$. The two observed peaks in this region correspond to aniline cation radical and protonated aniline, as shown.

The R2PI spectrum obtained by scanning the excitation laser while integrating the signal over the protonated aniline mass channel is compared with the bromobenzene R2PI spectrum in the upper panel of Fig. 2. The spectrum is similar to that observed for the $\mathrm{PhCl} \cdots \mathrm{NH}_{3}$ dimer in: 1 ) the appearance of an origin blue-shifted from the monomer, and 2) a strongly diagonal transition exhibiting little vibronic activity. Moreover, the magnitude of the blue-shift from the monomer origin follows the trend observed for the $\mathrm{PhF} \cdots \mathrm{NH}_{3}$ and $\mathrm{PhCl} \cdots \mathrm{NH}_{3}$ dimers, as shown in the lower panel of Fig. 2. This data provides strong evidence that the species responsible for the mass peaks observed in Fig. 1 is a $\sigma$-type $\mathrm{PhBr}$... NH $\mathrm{NH}_{3}$ dimer.

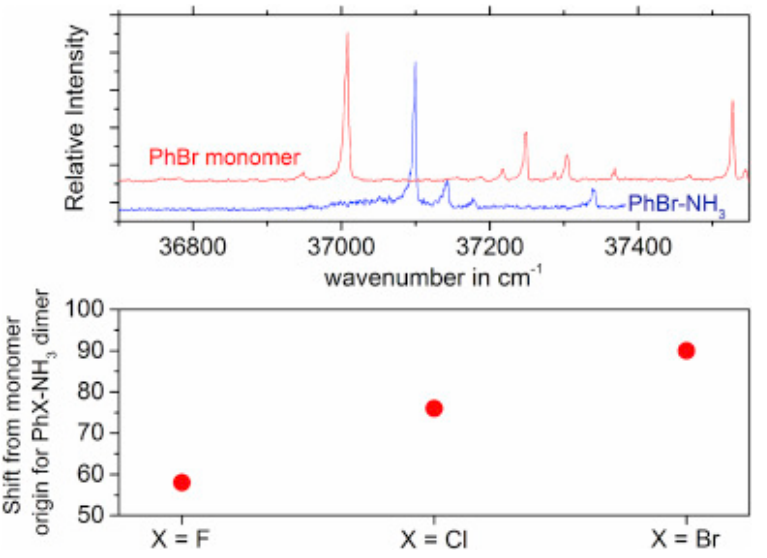

Fig. 2. Upper panel: comparison of R2PI spectra of the $\mathrm{PhBr}$ monomer and $\mathrm{PhBr}-\mathrm{NH}_{3}$ complex. The latter spectrum was obtained by monitoring the protonated aniline mass channel. Lower panel: trend in the blue-shift of the dimer excitation spectrum for $\mathrm{PhX}-\mathrm{NH}_{3}$ dimers $(\mathrm{X}=\mathrm{F}, \mathrm{Cl}, \mathrm{Br}$ ), data taken from refs. 26 and 27. (For interpretation of the references to color in this figure legend, the reader is referred to the Web version of this article.)

Additional evidence is provided by theory. Initial geometry optimizations at the M06-2X/aug-cc-pVTZ level identified four minima, with structures shown in Fig. S1 in the supporting information (SI). These correspond to two in-plane $\sigma$-type complexes (D1, D2), a halogen bonded complex (D3), and a $\pi$-type complex (D4). At this level of theory, the calculated binding energies, counterpoise and ZPE corrected, of D1 and D4 are similar, $\sim 6.5 \mathrm{~kJ} / \mathrm{mol}$, while the halogen bonded dimer D3 is bound by $3.7 \mathrm{~kJ} / \mathrm{mol}$, and D2 by $2.9 \mathrm{~kJ} / \mathrm{mol}$. However, binding energies at the explicitly-correlated coupled-cluster level are significantly different, and clearly favor D1. At the CCSD(T)-F12a/VDZ-F12 level (with M06-2X ZPE corrections), the binding energies are: 8.38, 4.25, 5.98, and $5.99 \mathrm{~kJ} / \mathrm{mol}$ for structures D1-D4 respectively.

As shown in Fig. S2 in SI, TDDFT calculations predict a blue-shift of the dimer origin for the $\sigma$-type complex D1 relative to the $\mathrm{PhBr}$ monomer, while the $\pi$-type complex (D4) is predicted to show a small red-shift. Indeed, when scaled to the experimental transition energy, the magnitude of the blue shift for D1 is in good agreement with experiment (Fig. S2), as was also found for the $\mathrm{PhCl} \cdots \mathrm{NH}_{3}$ dimer [27]. Thus, the position of the observed origin is also consistent with assignment to the $\sigma$-type complex D1.

Further evidence comes from Franck-Condon simulations, based upon the optimized geometries, vibrational frequencies, and mass-weighted normal mode displacements for the ground and excited states, incorporating the full effect of Duschinsky rotation [46]. These calculations, carried out with the Pgopher suite [45], were performed for the $\sigma$-type complex D1 and the $\pi$-type conformer (D4), and only the lowest frequency modes (maximum of 5) were included in the simulation. Fig. S3 in SI shows the simulated electronic spectra with an 
overlay of the experimental spectrum. Stick spectra were transformed into continuous spectra by convolution with a Gaussian function of $5 \mathrm{~cm}^{-1}$ full width at half-maximum. The simulation for the $\pi$-type (D4) isomer shows extended Franck-Condon progression, arising from the significant change in equilibrium geometry from the ground to the excited state, and is in direct contrast with the origin-dominated experimental spectrum. However, the simulated spectrum of the $\sigma$-type (D1) complex well matches the experimental spectrum, providing additional support for assignment of the observed electronic spectrum to the $\sigma$-type complex D1.

Having reasonably established the structure of the dimer, we now turn to the reactive pathways operative upon ionization. Based upon our prior findings for the $\mathrm{PhCl} \cdots \mathrm{NH}_{3}$ dimer [27], shown in Fig. 3(a), we believed that the cation radical PES should feature an arenium ion (Wheland) intermediate produced from ipso addition, which would react to yield both atomic and molecular products. However, the calculated stationary points for the ionized $\mathrm{PhBr} \cdots \mathrm{NH}_{3}$ dimer, Fig. 3 (b), are strikingly different. The intermediate produced from ipso addition does not correspond to a classic Wheland structure; rather, it is a distonic ion-radical complex of protonated aniline and a bromine atom. The latter is pushed quite far from the aromatic ring, so that the distance to the ipso carbon $(3.30 \AA)$ is significantly larger than the distance to the nearest amino hydrogen ( $2.53 \AA$ ) ; Fig. S4. Calculations at the B1LYP-40/6-31G(d) level reveal that the radical density is largely localized on the bromine atom, Fig. S5.

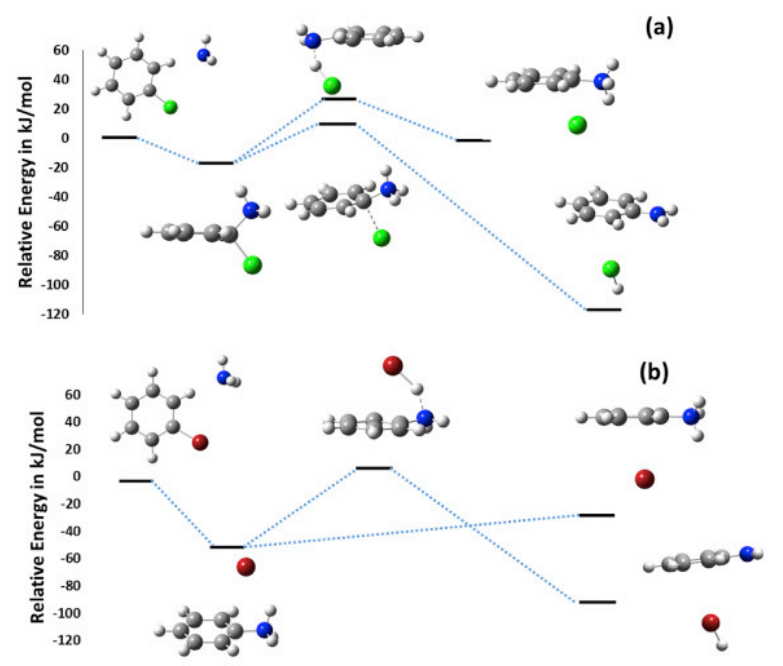

Fig. 3. (a) Calculated stationary points on the cation radical surface of the $\mathrm{PhCl} \cdots \mathrm{NH}_{3}$ system. (b) Similar calculations for the $\mathrm{PhBr} \cdots \mathrm{NH}_{3}$ dimer.

This change in intermediate structure leads to manifest differences in the resulting decay pathways, i.e.,

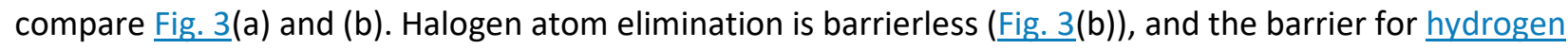
halide elimination is significantly increased in comparison with the $\mathrm{PhCl} \cdots \mathrm{NH}_{3}$ system. Similar to the dimer calculations, the energies plotted in Fig. 3 were obtained as single-point UCCSD(T)-F12a/VDZ-F12 energies, ZPE corrected at the M06-2X/aug-cc-pVTZ level. Additional data from the DFT calculations are provided in the supporting information (Figs. S6 and S7). As a further check, we also performed a full optimization of the distonic intermediate at the CCSD/aug-cc-pVTZ level (Fig. S8). The structure is similar to that obtained with DFT methods.

Using the calculated stationary points on the cation radical PES, we performed microcanonical transition state theory calculations to predict the relative branching between atomic and molecular products. The input parameters are provided in Table S1 in SI. As the ionization energy of the $\mathrm{PhBr} \cdots \mathrm{NH}_{3}$ dimer is unknown, we estimated the dimer IP by subtracting the IP decrease observed for the $\mathrm{PhCl} \cdots \mathrm{NH}_{3}$ dimer relative to $\mathrm{PhCl}$ $(-0.30 \mathrm{eV})[25]$ from the known IP of $\mathrm{PhBr}(8.98 \mathrm{eV})$ [47]. Coupled with the relative calculated stationary point 
energies (Fig. 3), we then can estimate that our two-photon energy produces the reactive intermediate with an energy of $1.25 \mathrm{eV}\left(10,100 \mathrm{~cm}^{-1}\right)$ above its zero-point level. At this energy, the statistical branching into the molecular channel is less than $1 \%$, much smaller than found experimentally. This again lies in contrast to the $\mathrm{PhCl} \cdots \mathrm{NH}_{3}$ system, where the experimental branching was well reproduced by statistical predictions [27].

What is the cause of this discrepancy? Reflecting on the distonic nature of the intermediate, i.e., where the ion and radical sites are distinct, we recognize that a roaming radical pathway is likely present. The roaming radical mechanism [48], [49], [50], first identified in neutral reactions in the photodissociation of formaldehyde [51], [52], [53], [54], can occur in barrierless bond-breaking, when the departing radicals can be trapped in the relatively flat exit channel PES, and explore trajectories which lead to re-encounter and the possibility of abstraction producing molecular products [55], [56]. Essentially, a roaming path offers a different route to molecular products which bypasses the tight transition state (TS). Often a distinct rovibrational distribution is observed for the roaming products. Klippenstein et al. emphasize describing orientational dynamics in the long range as roaming, even when the tight TS is too high in energy to contribute, and hence no bimodal product distribution is obtained [57]. In these cases the roaming fraction can be large. As the intermediate here is a distonic ion-radical complex, with no evident dissociation barrier for the radical channel, and the tight TS is much higher in energy, this is also the case here. It is noteworthy that roaming or "orbiting resonances" have been discussed in the ion-molecule community for some time and continue to be explored [58], [59], [60], [61], [62], [63], [64], [65].

The majority of studies of roaming have focused on hydrogen atoms, recent studies have provided evidence for "heavy-atom (or heavy-group)" roaming [55], [66], [67], [68], [69], [70], [71], [72]. To illustrate the roaming landscape of this system, a grid of $961(31 \times 31)$ points were generated at the M06-2X/aug-cc-pVTZ level, describing the interaction of a $\mathrm{Br}$-atom with the $\mathrm{Ph}-\mathrm{NH}_{3}$ cation. Fig. 4 maps the interaction energy relative to separated fragments, placing the $\mathrm{Br}$-atom on a square grid of points (in the plane of the heavy atoms) ranging from -7.5 to $7.5 \AA$ in both the $X$ - and $Y$-directions from the center-of-mass of the $\mathrm{Ph}^{-} \mathrm{NH}_{3}$ fragment.

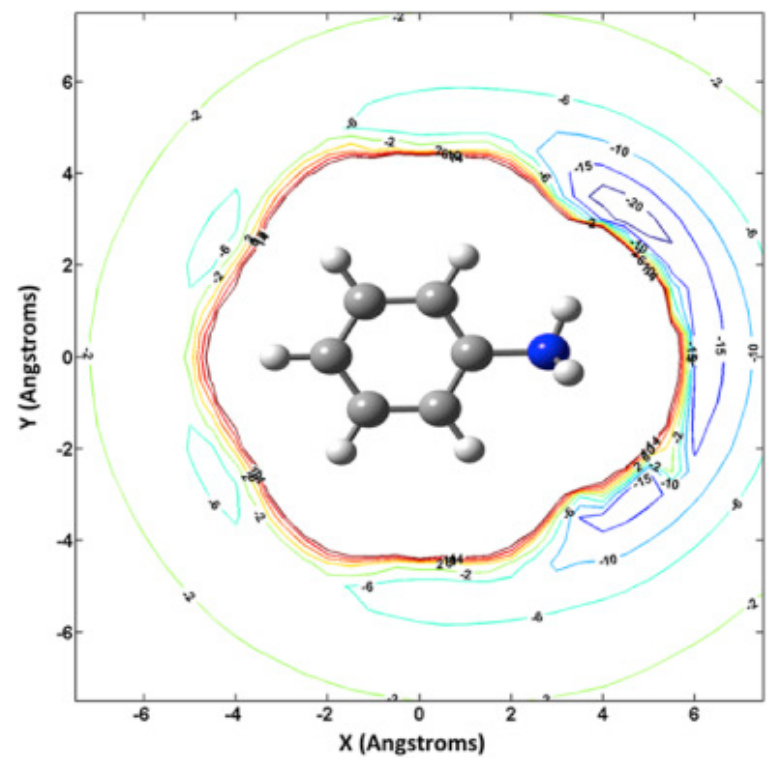

Fig. 4. Contour plot of the interaction between the roaming $\mathrm{Br}$-atom and the $\mathrm{Ph}-\mathrm{NH}_{3}$ fragment. Labeled contours indicate the energy in $\mathrm{kJ} / \mathrm{mol}$ and illustrate the attractiveness of the $\mathrm{NH}_{3}$ protons to the roaming $\mathrm{Br}$-atom.

More detailed experiments such as ion imaging, are currently planned in the Marquette group, in order to gain further insight into the roaming process. 


\section{Conclusions}

Building upon our recent studies of reactive pathways following resonant two-photon ionization in the $\mathrm{PhCl} \cdots \mathrm{NH}_{3}$ dimer, we have examined the spectroscopy and dynamics of the $\mathrm{PhBr} \cdots \mathrm{NH}_{3}$ dimer, for the first time. As for other $\mathrm{PhX} \cdots \mathrm{NH}_{3}$ dimers, the structure of the complex found experimentally corresponds to an in-plane $\sigma$ type complex, which theory confirms is the most stable minimum on the dimer PES.

Upon ionization, an intermediate is formed which reacts to yield molecular $(\mathrm{HBr})$ and atomic $(\mathrm{Br})$ products. As opposed to the $\mathrm{PhCl} \cdots \mathrm{NH}_{3}$ system, where the cation radical intermediate formed upon ipso addition has a classic arenium ion structure, our calculations predict that the reactive intermediate in the $\mathrm{PhBr} \cdots \mathrm{NH}_{3}$ system corresponds to a distonic ion-radical complex of protonated aniline and a $\mathrm{Br}$ atom. The calculated barrier to $\mathrm{HBr}$ loss is sufficiently high to render this channel insignificant $(<1 \%)$ in TST calculations, yet experiment shows a substantial (37\%) branching into this channel, higher even than that observed in the $\mathrm{PhCl} \cdots \mathrm{NH}_{3}$ system, where the branching was well modeled by TST. Since the tight TS is even higher in energy in this system, we rationalize these results in terms of a roaming radical mechanism for $\mathrm{HBr}$ formation.

\section{Acknowledgements}

Support of this research by the National Science Foundation is gratefully acknowledged. This research was also supported in part by National Science Foundation awards OCI-0923037 “MRI: Acquisition of a Parallel Computing Cluster and Storage for the Marquette University Grid (MUGrid)" and CBET-0521602 "Acquisition of a Linux Cluster to Support College-Wide Research \& Teaching Activities". R.D. acknowledges support from the U.S. Department of Energy (Grant No. DE-SC0010616).

\section{Appendix A. Supplementary data}

The following is the supplementary data related to this article: Download Word

document (2MB)Help with docx files

mmc1.

\section{References}

[1] Pierangelo Metrangolo, Jane S. Murray, Tullio Pilati, Peter Politzer, Giuseppe Resnati, G. Terraneo Cryst. Growth Des., 11 (9) (2011), pp. 4238-4246

[2] K.E. Riley, K.M. Merz Jr. J. Phys. Chem. A, 111 (2007), p. 1688

[3] P. Politzer, J.S. Murray, M.C. Concha J. Mol. Model., 13 (2007), p. 643

[4] H. Tachikawa, M. Igarashi J. Phys. Chem. A, 102 (1998), p. 8648

[5] R.N. Barnett, A. Bongiorno, C.L. Cleveland, A. Joy, U. Landman, G.B. Schuster J. Am. Chem. Soc., 128 (2006), p. 10795

[6] M. Miyazaki, A. Fujii, T. Ebata, N. Mikami Chem. Phys. Lett., 349 (2001), p. 431

[7]

H. Harada, H. Nagai, N. Mine, Y. Terada, H. Fujiwara, I. Mikami, M. Tsuneizumi, A. Yabe, K. Miyazaki, M. Y okota, I. Imoto, J. Inazawa, M. Emi J. Hum. Genet., 46 (2001), p. 70

[8] E.A. Meyer, R.K. Castellano, F. Diederich Angew. Chem. Int. Ed., 42 (2003), p. 1210

[9] S. Ionov, G. Brucker, C. Jaques, L. Valachovic, C. Wittig J. Chem. Phys., 99 (1993), p. 6553

[10] S. Ionov, G. Brucker, C. Jaques, L. Valachovic, C. Wittig J. Chem. Phys., 97 (1992), p. 9486

[11] Y. Chen, G. Hoffmann, D. Oh, C. Wittig Chem. Phys. Lett., 159 (1989), p. 426 
[12] C. Wittig, S. Sharpe, R. Beaudet Accounts Chem. Res., 21 (1988), p. 341

[13] B. Brutschy Ber. Bunsen Phys. Chem., 96 (1992), p. 1154

[14] B. Brutschy, J. Eggert, C. Janes, H. Baumgartel J. Phys. Chem., 95 (1991), p. 5041

[15] T. Maeyama, N. Mikami J. Phys. Chem., 95 (1991), p. 7197

[16] T. Maeyama, N. Mikami J. Phys. Chem., 94 (1990), p. 6973

[17] S. Vaupel, B. Brutschy, P. Tarakeshwar, K.S. Kim J. Am. Chem. Soc., 128 (2006), p. 5416

[18] B. Wassermann, B. Brutschy J. Mol. Struct., 103 (1993), p. 107

[19] C. Riehn, C. Lahmann, B. Brutschy, H. Baumgartel 96 (1992), p. 1164

[20]C. Riehn, J. Avdiew, J. Eggert, B. Wassermann, B. Brutschy, H. Baumgartel J. Mol. Struct., 249 (1991), p. 33

[21] B. Brutschy J. Phys. Chem., 94 (1990), p. 8637

[22] H. Baumgartel, B. Brutschy, E. Ruhl Phys. Scr., T31 (1990), p. 78

[23] J. Eggert, C. Janes, B. Wassermann, B. Brutschy, H. Baumgartel Ber. Bunsen Phys. Chem., 94 (1990), p. 1282

[24] K. Butterworth, C. Chiang, B. Cunningham, M. Freindorf, T. Furlani, R. DeLeon, J. Garvey J. Phys. Chem. A, 116 (2012), p. 1877

[25] J. Grover, B. Cheng, W. Herron, M. Coolbaugh, W. Peifer, G. JF J. Phys. Chem., 98 (1994), p. 7479

[26] N.M. Tonge, E.C. MacMahon, I. Pugliesi, M.C.R. Cockett J. Chem. Phys. (2007), p. 126

[27] S.A. Reid, S. Nyambo, A. Kalume, B. Uhler, C. Karshenas, L. Muzangwa J. Phys. Chem. A, 117 (2013), p. 12429

[28] J. Grover, W. Herron, M. Coolbaugh, W. Peifer, J. Garvey J. Phys. Chem., 95 (1991), p. 6473

[29] D. Karlsson, O. Borg, S. Lunell, J. Davidsson, H. Karlsson J. Chem. Phys. (2008), p. 128

[30] D. Karlsson, J. Davidsson J. Photochem. Photobiol. Chem., 195 (2008), p. 242

[31] A. Andrejeva, W. Tuttle, J. Harris, T. Wright J. Chem. Phys. (2015), p. 143

[32] B. Koplitz, J. McVey J. Chem. Phys., 80 (1984), p. 2271

[33] B. Koplitz, J. McVey J. Chem. Phys., 81 (1984), p. 4963

[34] T. Dietz, M. Duncan, M. Liverman, R. Smalley J. Chem. Phys., 73 (1980), p. 4816

[35] Frisch, M. J.; Gaussian Inc.: Pittsburg, PA, 2009.

[36] Yan Zhao, Donald G. Truhlar Theor. Chem. Acc., 120 (2008), pp. 215-241

[37] N. Mardirossian, J.A. Parkhill, M. Head-Gordon Phys. Chem. Chem. Phys., 13 (2011), p. 19325

[38] Werner, H. J.; Knowles, P. J.; Knizia, G.; Manby, F. R.; Schutz, M. 2015.

[39] T.B. Adler, G. Knizia, H.J. Werner J. Chem. Phys. (2007), p. 127

[40] G. Knizia, T.B. Adler, H.J. WernerJ. Chem. Phys. (2009), p. 130

[41] J.G. Hill, K.A. Peterson J. Chem. Phys. (2014), p. 141

[42] M.R. Talipov, A. Boddeda, Q.K. Timerghazin, R. Rathore J. Phys. Chem. C, 118 (2014), p. 21400

[43] M. Renz, K. Theilacker, C. Lambert, M. Kaupp J. Am. Chem. Soc., 131 (2009), p. 16292

[44] M. Renz, M. Kess, M. Diedenhofen, A. Klamt, M. Kaupp J. Chem. Theory Comput., 8 (2012), p. 4189

[45] PGOPHER (2010)

[46] H. Kupka, P.H. Cribb J. Chem. Phys., 85 (1986), p. 1303

[47] P. Linstrom, W. Mallard J. Chem. Eng. Data, 46 (2001), p. 1059

[48] J. Bowman, A. Suits Phys. Today, 64 (2011), p. 33

[49] J. Bowman, B. Shepler, L. Sr, P. Cremer, J. Groves, M. JohnsonAnnu. Rev. Phys. Chem., 62 (2011), p. 531

[50] N. Herath, A. Suits J. Phys. Chem. Lett., 2 (2011), p. 642

[51]S. Lahankar, S. Chambreau, X. Zhang, J. Bowman, A. Suits J. Chem. Phys. (2007), p. 126

[52] A. Suits, S. Chambreau, S. Lahankar Int. Rev. Phys. Chem., 26 (2007), p. 585

[53]S. Chambreau, D. Townsend, S. Lahankar, S. Lee, A. Suits Phys. Scr., 73 (2006), p. C89

[54] S. Lahankar, S. Chambreau, D. Townsend, F. Suits, J. Farnum, X. Zhang, J. Bowman, A. Suits J. Chem. Phys. (2006), p. 125

[55] H. Li, P. Tsai, K. Hung, T. Kasai, K. Lin J. Chem. Phys. (2015), p. 142 
[56] K.L.K. Lee, M.S. Quinn, A.T. Maccarone, K. Nauta, P.L. Houston, S.A. Reid, M.J.T. Jordan, S.H. Kable Chem. Sci., 5 (2014), p. 4633

[57] S.J. Klippenstein, Y. Georgievskii, L.B. Harding J. Phys. Chem. A, 115 (2011), p. 14370

[58] L.N. Ding, M.A. Young, P.D. Kleiber, W.C. Stwalley, A.M. Lyyra J. Phys. Chem., 97 (1993), p. 2181

[59] A.E. Belikov, M.A. Smith Int. J. Mass Spectrom., 246 (2005), p. 43

[60] A.E. Belikov, M.A. Smith Chem. Phys. Lett., 387 (2004), p. 7

[61] A.E. Belikov, C. Mullen, M.A. Smith J. Chem. Phys., 114 (2001), p. 6625

[62] B.K. Bluhm, S.W. North, D.H. RussellJ. Chem. Phys., 114 (2001), p. 1709

[63] F.A.L. Mauguiere, P. Collins, G.S. Ezra, S.C. Farantos, S. Wiggins J. Chem. Phys. (2014), p. 140

[64] B. Xiong, Y.C. Chang, C.Y. Ng Phys. Chem. Chem. Phys., 19 (2017), p. 29057

[65]T. Michaelsen, B. Bastian, E. Carrascosa, J. Meyer, D.H. Parker, R. Wester J. Chem. Phys. (2017), p. 147

[66] R. Fernando, A. Dey, B. Broderick, B. Fu, Z. Homayoon, J. Bowman, A. Suits J. Phys. Chem. A, 119 (2015), p. 7163

[67] A. Suits, R. Fernando, A. Dey Abstr. Pap. Am. Chem. Soc. (2014), p. 248

[68] B. Joalland, Y. Shi, A. Estillore, A. Kamasah, A. Mebel, A. Suits J. Phys. Chem. A, 118 (2014), p. 9281

[69]S. North, M. Grubb, M. Warter Abstr. Pap. Am. Chem. Soc. (2013), p. 245

[70] B. oalland, R. Van Camp, Y. Shi, N. Patel, A. Suits J. Phys. Chem. A, 117 (2013), p. 7589

[71] M. Grubb, M. Warter, H. Xiao, S. Maeda, K. Morokuma, S. North Science, 335 (2012), p. 1075

[72] H. Xiao, S. Maeda, K. Morokuma J. Phys. Chem. Lett., 2 (2011), p. 934 